\title{
JOURNAL.RU
}

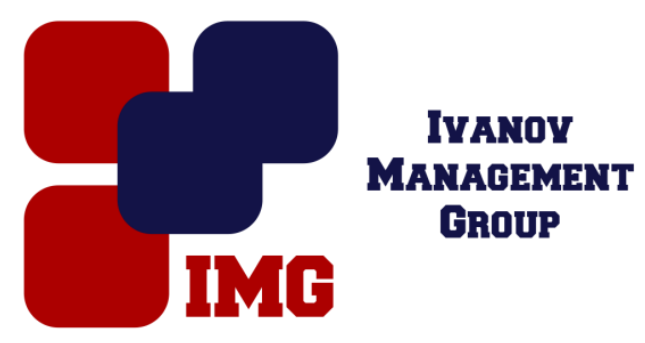

Павлов Б.В., Зеленева Ю.В.

Тамбовский государственный университет имени Г.Р. Державина Тамбов, Россия

doi: $10.18411 / 1 \mathrm{j}-31-07-2017-26$

idsp 000001:1j-31-07-2017-26

\section{Осложнения при сахарном диабете}

\section{Аннотация}

В статье рассматривается влияние сахарного диабета на организм человека: раскрывается сущность сахарного диабета, механизм действия на организм человекаи последствия перенесённого заболевания.

Ключевые слова: сахарный диабет, диабетическая энцефалопатия, диабетическая ретинопатия, инфаркт миокарда, диабетическая нефропатия, диабетическая нейропатия, гангрена при сахарном диабете.

Сахарный диабет- группа эндокринных заболеваний, развивающихся вследствие абсолютной или относительной недостаточности гормона инсулина, в результате чего развивается гипергликемия - стойкое увеличение содержания глюкозы в крови.

Обычно встречаются 2 типа сахарного диабета: диабет первого и второго типа.

Сахарный диабет 1 типа (инсулинозависимый диабет) возникает вследствие прямого разрушения клеток поджелудочной железы, производящих гормон инсулин. Неконтролируемый сахарный диабет оказывает влияние на все органы человека. Когда организм неспособен утилизировать глюкозу, мозг и другие органы истощаются, даже при том, что человек может потреблять большое количество пищи. Организм старается восполнить необходимую энергию путем метаболизма жиров, что приводит к образованию кетонов - 
токсических веществ, которые могут оказывать повреждающее действие на мозг и вызывать кому.

Сахарный диабет 2 типа сопровождается нормальной или повышенной выработкой инсулина. Причиной развития заболевания является несвоевременное поступление инсулина в кровь, а также снижение чувствительности клеток тела пациента к инсулину. Сахарный диабет 2-го типа раньше называли «инсулиннезависимым диабетом», вследствие того, что лечение заболевания не включало использование инъекций искусственного инсулина. В настоящее время некоторым пациентам со 2-м типом диабета требуется введение инсулина, но для этого типа сахарного диабета инсулинотерапия не является основным методом лечения.

Сахарный диабет не представляет серьезную угрозу, но характеризуется скачкообразностью повышения или понижения сахара в крови, вследствиие которой при постоянной декомпенсации диабета, начинается поражение органов-мишеней таких как: мозг, глаза, сердце и ноги.[1]

Диабетическая энцефалопатия (ДЭ) - это поражение структур центральной нервной системы (головного мозга) в результате метаболических нарушений на фоне сахарного диабета. Из-за плохого питания и кровообращения головного мозга вызывается энцефалопатия, чаще всего у диабетиков первого типа (80\%) (Рисунок 1$)$.

\section{Население около 15 тыс.}

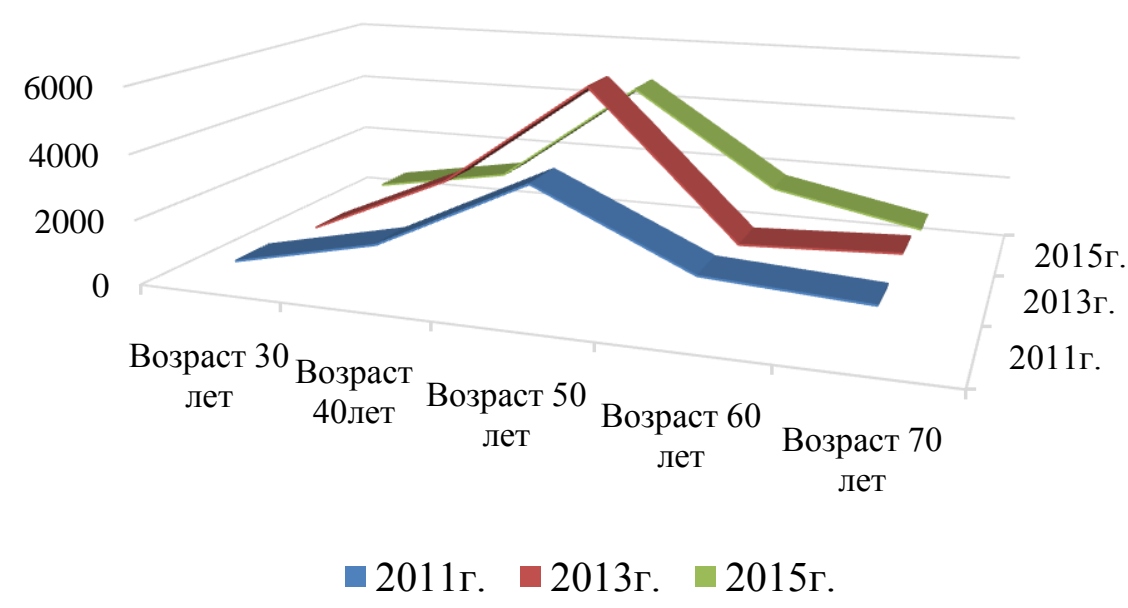

Рисунок1. Статистика диабетической энцеералопатии при диабете 2-го типа в РФ 


\section{Население около 50 тыс.}

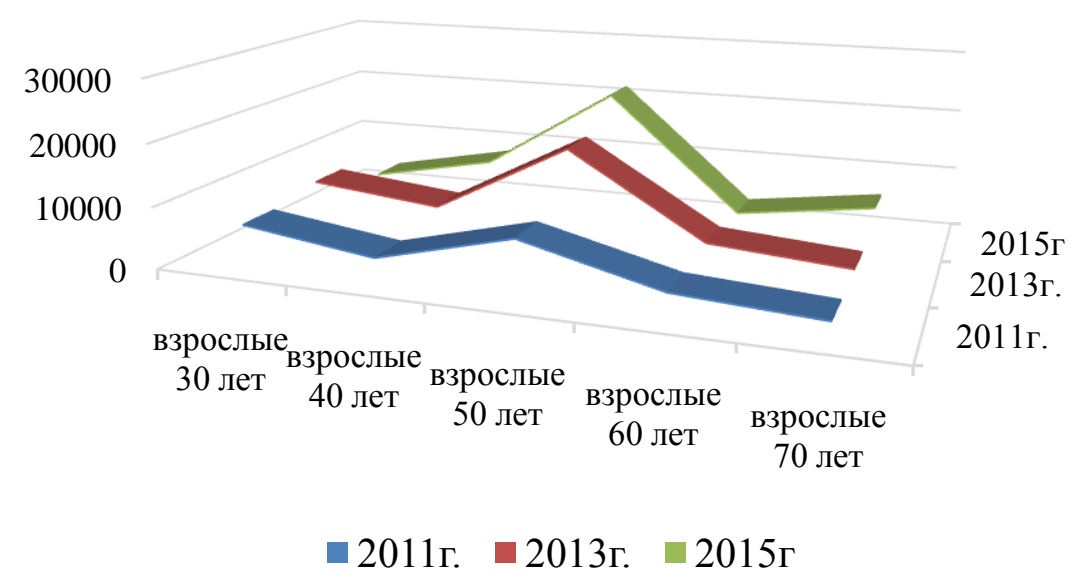

Рисунок 2. Статистика диабетической ретинопатии при диабете 2-го типа в РФ.

Диабетическая ретинопатия - поражение сосудов сетчатой оболочки глазного яблока. Это тяжелое и очень частое осложнение диабета, которое может привести к слепоте. Осложнения на зрение наблюдаются у 85\% больных диабетом 1 типа со стажем 20 лет и более. Когда обнаруживают диабет 2 типа у людей среднего и пожилого возраста, то более чем в 50\% случаев у них сразу выявляют поражение сосудов, питающих кровью глаза. Осложнения диабета это наиболее частая причина новых случаев слепоты среди взрослых людей в возрасте от 20 до 74 лет (Рисунок 2). [2]

Инфарктмиокарда - одна из клинических форм ишемической болезни сердца, протекающая с развитием ишемического некроза участка миокарда, обусловленного абсолютной или относительной недостаточностью его кровоснабжения. У диабетиков инфаркты и, конечно же, инсульты возникают в раннем возрасте, что и является основополагающим отличием от обычных здоровых людей. Вообще, инфаркт миокарда и сахарный диабет - это наитяжелейшие заболевания, требующие внимательного контроля и быстротечного лечения.

Особенностями инфаркта при сахарном диабете первого или второго типа являются:

$>$ резкий скачок глюкозного уровня в крови, провоцирующий отложение холестерина на сосудистых стенках;

появление бляшек атеросклеротического характера;

значительное сужение просветов и так далее. 
Вышеуказанные образования считаются основополагающими причинами развития ишемических заболеваний сердца, то есть стенокардии, сердечной недостаточности, аритмии, инфаркта. Известно, что сахарный диабет по своей сущности имеет возможность сильно изменять кровь, при этом делая ее очень вязкой, густой. В таком случае инфаркт будет развиваться в несколько раз тяжелее (Рисунок 3). [3]

\section{Населения около 20 млн}

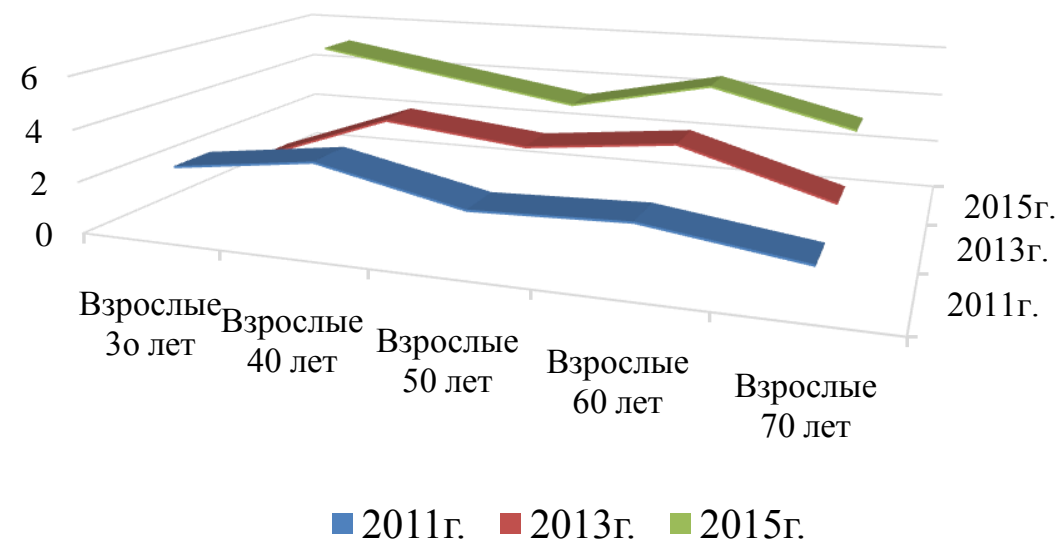

Рис.3 Статистика инфаркта миокарда при сахарном диабете 2-го типа в РФ

Диабетическая нефропатия - двустороннее поражение почек, приводящее к снижению функциональной способности, и возникающее по причине влияния различных патологических эффектов, формирующихся при сахарном диабете.

Диабетическая нейропатия - поражение нервной системы вследствие сахарного диабета. Нейропатия является самым частым осложнением заболевания. При этом в патологический процесс могут вовлекаться различные отделы нервной системы, приводя к соответствующим клиническим проявлениям (Рисунок 4). [4] 


\section{Население около 200 тыс.}

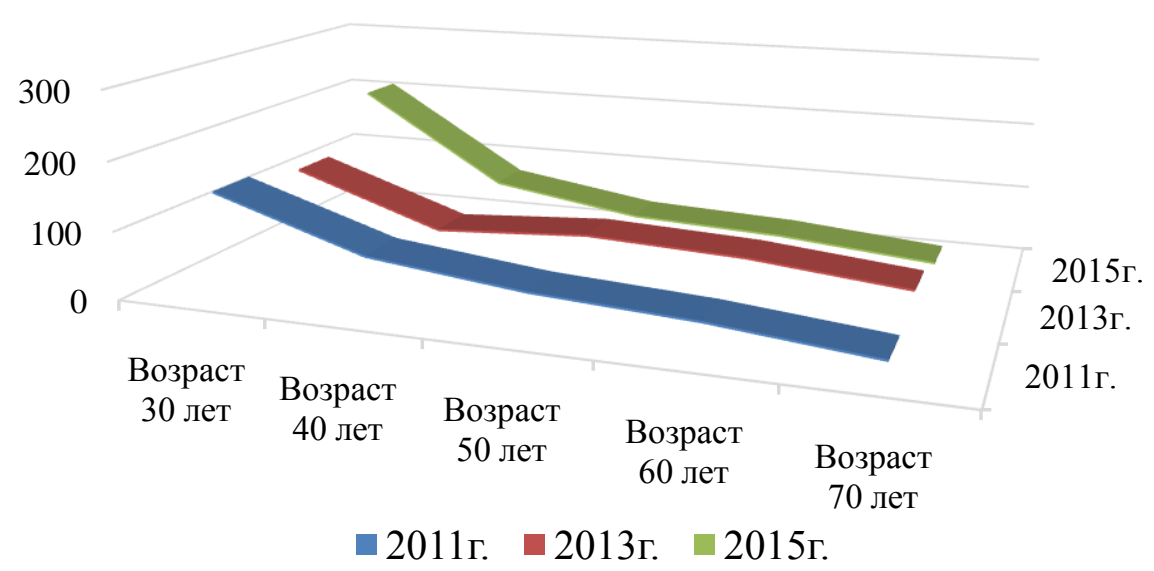

Рис.4 Статистика диабетической нейропатии при сахарном диабете 2-го типа

Гангрена - омертвление клеток какого-либо органа или части тела. Гангрена при сахарном диабете встречается очень часто. Это самое опасное осложнение данного недуга. Такой процесс можно объяснить тем, что кровеносные сосуды из-за большого содержания сахара в крови перестают функционировать, и к клеткам перестает поступать кровь. По статистике $60 \%$ инсулинозависимых людей страдают гангреной. [5]

Таким образом, анализируя статистические данные, можно наблюдать прогрессивный рост заболеваемости сахарного диабета, сопровождаемый осложнениями: инфарктом миокарда, гангреной, язвами, вплоть до летального исхода; ретинопатии, нейропатии и нефропатии значительно уменьшают уровень жизнедеятельности пациента.

По данным Росстата Россия входит в пятерку стран мира по заболеваемости населения сахарным диабетом. На территории страны насчитывается более 280 тысяч диабетиков, имеющих заболевание первого типа. Эти люди зависят от ежедневного введения инсулина, среди них 16 тысяч детей и 8,5 тысяч подростков. 
1. Актуальные вопросы терапии и обучения пациентов с сахарным диабетом [Электронный ресурс]: цикл веб-конференций. - 3,41 Кб. - Москва. - 2013. [4]

2. Актуальные вопросы эндокринологии в терапевтической практике: рук. для врачей / М.Н. Калинкин, Л.В. Шпак, Ю.А. Волкова, Е.И. Березина, Д.В. Килейников, О.А. Лаздин, И.В. Медведева, С.А. Смирнов, С.Н. Бельдиев, Е.В. Андреева; ред. М.Н. Калинкин, Л. В. Шпак. - Тверь: Фактор и К. - 2014. - с. 691 - 698. [2]

3. Князев, Ю.А. Сахарный диабет / Ю.А. Князев, И.И. Никберг // Москва, изд-во «Медицина». - 1989. - 143 с. [1]

4. Лаптенок, Л.В. Пособие для больных сахарным диабетом / Л.В. Лаптенок // Минск, издво «Беларусь». - 1989. - 144 с. [3], [5]

5. http://www.gks.ru. [дата обращения: 15.04.2016]

6. Данные были взяты из областной клинической больницы на базе университета им. Максима Горького г. Донецка в 2016 (ДНР).[дата обращение апрель 2016]. 